\title{
Trophic action of epidermal growth factor on human duodenal mucosa cultured in vitro
}

\author{
D N Challacombe, E E Wheeler
}

\begin{abstract}
The action of epidermal growth factor on the human duodenal mucosa has been studied by estimating the crypt cell production rate in cultured explants, using a stathmokinetic technique with crypt microdissection. The addition of epidermal growth factor $(400 \mathrm{ng} / \mathrm{ml})$ to paired explants from five patients caused an almost fivefold increase in the crypt cell production rate, showing that epidermal growth factor has a trophic action on the human duodenal mucosa in vitro.
\end{abstract}

Epidermal growth factor, a polypeptide containing 53 amino acids, was first isolated from urine.' In the small intestine, it is secreted directly into the lumen by Brunner's glands and it is also present in salivary and biliary secretions, colostrum, and breast milk. Epidermal growth factor has biological effects throughout the gastrointestinal tract, including the stimulation of ornithine decarboxylase and DNA synthe$\mathrm{sis}^{2-4}$ the cytoprotection of the gastric mucosa, and the inhibition of gastric secretion. ${ }^{6}$ Epidermal growth factor stimulates the maturation and proliferation of the stomach and small intestine in fetal and neonatal animals ${ }^{7-9}$ and has trophic effects on other parts of the gastrointestinal tract in mature animals in vivo and in vitro..$^{10-15}$ In this investigation, the action of mouse epidermal growth factor on the crypt cell production rate has been studied in cultured explants of human duodenal mucosa, using a stathmokinetic technique with crypt microdissection. ${ }^{16}$

\section{Methods}

SMALL INTESTINAL BIOPSY SPECIMENS

Mucosal biopsy specimens from the third or fourth part of the duodenum were obtained by fibreoptic endoscope (Olympus GIF 1T) from five adults (four women, one man) undergoing investigation for upper gastrointestinal disorders. All specimens were expelled from the biopsy forceps into cold Leibowitz L-15 medium and flattened, serosal surface downwards, using aseptic techniques. Each specimen was then divided into pieces measuring approximately $3 \mathrm{~mm}^{2}$. Several specimens were selected for histopathology and fixed in $10 \%$ formal saline. Sections $(4 \mu \mathrm{m})$ were cut from each paraffin block, stained with haematoxylin and eosin and viewed by light microscopy.

Correspondence to:

Somerset Children's Research

Unit, Musgrove Park

Unit, Musgrove Park

Hospital,

Accepted for publication

5 November 1990 male mouse submaxillary glands and human

the morphological integrity of small intestinal explants for up to 25 hours in vitro (Fig 1). A rectangle of Gelfoam sponge $(20 \times 10 \times 7 \mathrm{~mm}$, Upjohn Co, Kalamazoo, USA), glued under sterile conditions with Dow Corning Medical 355 Adhesive to the base of a Lux multiwell culture dish (Flow Laboratories) was used to support the tissue samples. Thirty minutes before receiving the biopsy specimens the Gelfoam sponge in each culture well was saturated with $2 \mathrm{ml}$ of the serum free culture medium. Serum free medium was used as fetal calf serum could have contained growth factors that might have influenced the crypt cell production rate. Matched biopsy specimens from each patient acted as their own controls, and both test and control samples were cultured serosal surface downwards on a Gelfoam sponge in different culture wells under sterile conditions. The culture medium contained $9 \mathrm{ml}$ of CMRL 1066 medium, $0.75 \mathrm{ml}$ of penicillin and streptomycin (10000 IU of each), $0.025 \mathrm{ml}$ of Fungizone, $10 \mathrm{mg}$ of glucose, $0.5 \mathrm{mg}$ of insulin, $0.5 \mathrm{mg}$ of hydrocortisone 21-hemisuccinate, $0.05 \mathrm{mg}$ of ascorbic acid, and $0.1 \mathrm{ml}$ of Hepes $(1 \mathrm{~mol} / \mathrm{l})$. The medium was sterilised by filtration using a $0.2 \mu \mathrm{m}$ Acrodisc filter (Gelman Sciences). Epidermal growth factor (Collaborative Research Inc) derived from mouse submaxillary glands, was then added to the wells containing the test specimens giving a final concentration of $400 \mathrm{ng} /$ $\mathrm{ml}$. All dishes were covered with a lid (slightly raised to allow for gassing) and placed in a controlled atmosphere chamber (Bellco Glass Inc) containing a dish of sterile water to maintain humidity. The chamber was sealed, placed on a rocking apparatus in a $37^{\circ} \mathrm{C}$ incubator, and rocked at $4 \mathrm{rpm}$ in an atmosphere of $95 \%$ oxygen and $5 \%$ carbon dioxide.

CRYPT CELL PRODUCTION RATE

Both control and test specimens from each patient were identically maintained in organ culture for 22 hours before adding $0.7 \mu \mathrm{g} / \mathrm{ml}$ of vincristine sulphate (Oncovin, Lilly) to each culture well to start the stathmokinetic experiment. The dose of vincristine sulphate was derived from earlier studies. It was the lowest concentration (within the range of $0.1-3.0 \mu \mathrm{g} /$ $\mathrm{ml}$ ) that caused the greatest number of metaphase arrests/crypt over three hours, without allowing escape into anaphase to occur. After adding vincristine, two explants were removed from both control and text culture wells at hourly intervals for three hours and fixed in Carnoy's fluid for four hours. The specimens were stored in $70 \%$ alcohol before staining DNA by the Feulgen technique. Intestinal crypts in the conThe organ culture method used maintained trol and test samples were separated by micro- 


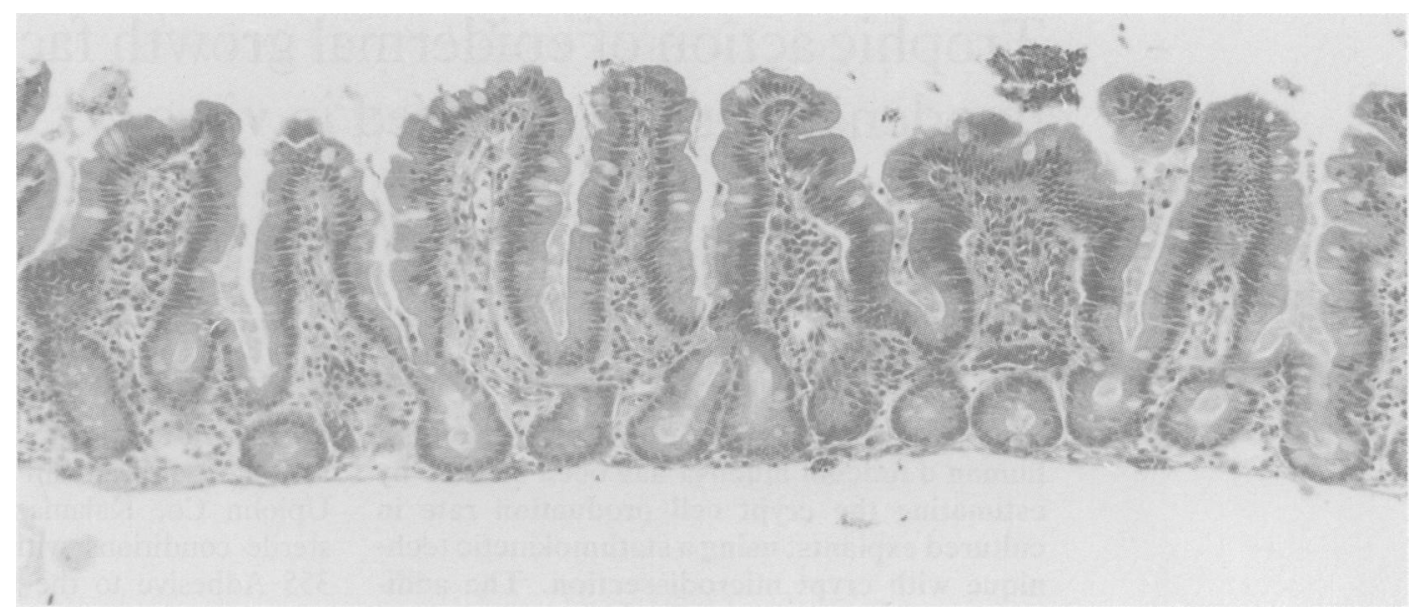

Figure 1: Human duodenal mucosa cultured in basic medium for 25 hours. (Haematoxylin and eosin, original magnification ×107.)

dissection in $45 \%$ acetic acid, squashed under a coverslip, and examined by light microscopy. The number of metaphase arrests in 15 crypts from different parts of each sample was counted and the mean numbers of metaphase arrests per crypt at each sampling time were plotted for both control and test specimens. The slope of the line joining these points fitted by least squares linear regression, gave the crypt cell production rate. Statistical analysis of the differences between test and control production rates was performed using a paired Student's $t$ test.

\section{Results}

Histological sections of the duodenal mucosa from all five patients were initially normal by light microscopy. After 25 hours of culture, the appearances were characterised by shortening of some villi with good preservation of the superficial epithelial cells (Fig 1). The crypt cell production rate values in the control and test samples are shown in the Table and Fig 2. The crypt cell production rate value in test explants with epidermal growth factor added to the serum free culture medium (mean (SEM), $5 \cdot 8(1 \cdot 4)$ cells/crypt/hour) was almost five times higher than in control explants $(1 \cdot 2(0 \cdot 2)$ cells/crypt/ hour) (paired $t$ test $\mathrm{p}<0.025)$. There was a close correlation between the number of metaphase arrests per crypt and time, in both test $(r=0.99)$ and control explants $(r=0.99)$.

Stathmokinetic study: metaphase arrests/crypt and crypt cell production rate $(C C P R)$ values in control and test duodenal specimens from five patients

\begin{tabular}{|c|c|c|c|c|c|c|}
\hline \multirow[b]{2}{*}{ Patients } & \multirow[b]{2}{*}{ Age (yrs) } & \multirow[b]{2}{*}{ Sex } & \multicolumn{3}{|c|}{ Metaphase arrests/crypt (mean) } & \multirow[b]{2}{*}{$C C P R$} \\
\hline & & & $1 \mathrm{hr}$ & $2 \mathrm{hr}$ & $3 h r$ & \\
\hline \multicolumn{7}{|l|}{ Controls } \\
\hline 1 & 72 & $\mathrm{~F}$ & $1 \cdot 4$ & $2 \cdot 0$ & $3 \cdot 0$ & $0 \cdot 8$ \\
\hline 2 & 89 & $M$ & $1 \cdot 0$ & $1 \cdot 5$ & $3 \cdot 4$ & $1 \cdot 2$ \\
\hline 3 & 84 & $\mathrm{~F}$ & $2 \cdot 3$ & $3 \cdot 4$ & $5 \cdot 1$ & $1 \cdot 4$ \\
\hline 4 & 78 & $\mathrm{~F}$ & $0 \cdot 4$ & 0.8 & $1 \cdot 4$ & 0.5 \\
\hline 5 & 65 & $\mathrm{~F}$ & $1 \cdot 0$ & $3 \cdot 4$ & 4.9 & 1.9 \\
\hline Mean (SEM) & & & $1 \cdot 2(0 \cdot 3)$ & $2 \cdot 2(0 \cdot 5)$ & $3 \cdot 6(0 \cdot 7)$ & $1 \cdot 2(0 \cdot 2)$ \\
\hline \multicolumn{7}{|c|}{ Tests (+epidermal growth factor) } \\
\hline 1 & 72 & $\mathrm{~F}$ & 6.9 & $7 \cdot 4$ & $13 \cdot 0$ & $3 \cdot 0$ \\
\hline 2 & 89 & $M$ & $7 \cdot 0$ & $16 \cdot 0$ & $23 \cdot 0$ & $8 \cdot 0$ \\
\hline 3 & 84 & $\mathrm{~F}$ & $7 \cdot 9$ & 14.9 & $27 \cdot 5$ & $9 \cdot 8$ \\
\hline 4 & 78 & $\mathbf{F}$ & $2 \cdot 2$ & $5 \cdot 0$ & $8 \cdot 3$ & $3 \cdot 0$ \\
\hline 5 & 65 & $\mathrm{~F}$ & $10 \cdot 8$ & $13 \cdot 4$ & $21 \cdot 0$ & $5 \cdot 1$ \\
\hline Mean (SEM) & & & $7 \cdot 0(1 \cdot 4)$ & $11 \cdot 3(2 \cdot 2)$ & $18 \cdot 6(3 \cdot 4)$ & $5 \cdot 8(1 \cdot 4)$ \\
\hline
\end{tabular}

\section{Discussion}

In this study, the addition of mouse epidermal growth factor to cultured explants of the normal human duodenum from five patients caused an almost fivefold increase in the crypt cell production rate compared with that of paired controls $(p<0.025)$. Previous studies have shown that the trophic effect of epidermal growth factor on rat colonic mucosa in organ culture was more pronounced in the presence of serum, ${ }^{17}$ suggesting an interaction between epidermal and additional growth factors in serum. As duodenal explants in this study were cultured in a serum free medium, the raised crypt cell production rate was more probably the result of the specific action of epidermal growth factor. Brunner's glands in the human duodenal mucosa are also a rich source of immunoreactive epidermal growth factor,$^{18}$ and the possibility that endogenous epidermal growth factor could have influenced the crypt cell production rate in both the control and test mucosal biopsy samples cannot be excluded.

The actual concentration of epidermal growth factor at the cell surface in the duodenal mucosa in vivo is difficult to estimate and the dose used in the present study $(400 \mathrm{ng} / \mathrm{ml})$ was similar to that found in human colostrum $(20-438 \mathrm{ng} / \mathrm{ml})$ and mature milk (20-110 ng/ml), and to doses used in previous in vitro culture experiments. ${ }^{22}{ }^{23}$ The first interaction between epidermal growth factor and the duodenal mucosa usually occurs after binding to specific receptors on the enterocytes, ${ }^{19-21}$ suggesting an important role for this polypeptide in maintaining gastrointestinal homeostasis. Parenteral administration of epidermal growth factor to suckling rodents stimulates intestinal growth and maturation, ${ }^{478}$ but similar experiments on adult animals have given equivocal results. ${ }^{30-13}$ Intestinal epithelial cell proliferation and growth also occur in a dose dependant manner after the intravenous (but not intragastric) administration of recombinant $\beta$ urogastrone-human epidermal growth factor to parenterally fed adult rats, suggesting a systemic rather than an intraluminal mechanism of action. ${ }^{15}$ In other studies, however, the intraluminal administration of epidermal growth factor also had a trophic effect on the duodenal mucosa of adult rats in vivo, ${ }^{11} 13$ and further investiga- 
Figure 2: Mean crypt cell production rates $(C C P R)$ for the control and test specimens of the duodenal mucosa. $\bullet$ Control, $n=5, y=-0.06+1.2 x$ oTest + EGF, $n=5, y=0.7+5.8 \times$

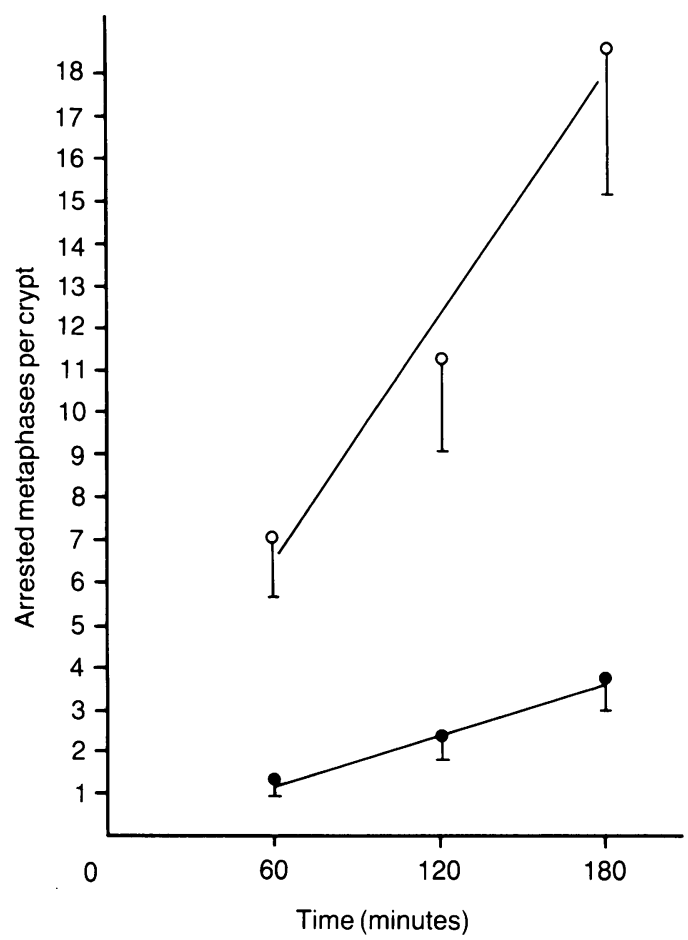

tions will be necessary to determine the exact site and mechanism of its action. ${ }^{10}$ In this study, epidermal growth factor added to the culture medium may have reached epithelial cell receptors in duodenal explants from either the mucosal or serosal surfaces. Mouse and rat epidermal growth factor have similar chemical, physical, and physiological properties to $\beta$ urogastrone, a peptide found in human urine which inhibits gastric acid secretion. $\beta$ urogastrone has been isolated and sequenced by Gregory $^{24}$ and contains 53 amino acids, 37 of which are common to both peptides. Human recombinant $\beta$-urogastrone epidermal growth factor has also been shown to be a potent stimulator of intestinal epithelial cell proliferation in adult rats. ${ }^{15} 25$ and in an infant with congenital microvillous atrophy. ${ }^{26}$ Exogenous epidermal growth factor may have a role in the prevention or reversal of mucosal atrophy in patients receiving parenteral nutrition and in stimulating epithelial cell regeneration after small intestinal resection.

The development of methods to culture explants of the human small intestinal mucosa in vitro and maintain their morphological integrity over increasing periods of time, has facilitated studies of the action of putative growth factors on epithelial cell kinetics. ${ }^{27}$ These methods may also be useful in investigating the mechanisms by which epidermal and other growth factors influence epithelial cell kinetics in the human small intestine.

We wish to thank Dr Michael Barry and Mrs Eve Sweet for their valuable assistance with this project which was generously supported by the South Western Regional Research Committee.
1 Savage RC, Cohen S. Epidermal growth factor and a new derivative. Rapid isolation procedures and biological and chemical characterisation. 7 Biol Chem 1972; 247: 7609-11.

2 Schieving LA, Yeh YC, Schieving LE. Circadian phasedependant stimulatory effects of epidermal growth factor on dependribonucleic acid synthesis in the tongue, oesophagus and stomach of the adult male mouse. Endocrinology 1979; and stomach of

3 Schieving LA, Yeh YC, Tsai TH, Schieving LE. Circadian phase-dependant stimulatory effects of epidermal growth factor on deoxyribonucleic acid synthesis in the duodenum, jejunum, ileum, caecum, colon, and rectum of the adult male mouse. Endocrinology 1980; 106: 1498-503.

4 Feldman EJ, Aures D, Grossman MI. Epidermal growth factor stimulates ornithine decarboxylase activity in the digestive tract of the mouse. Proc Soc Exp Biol Med 1978; 159: $400-2$.

5 Kirkegaard P, Olsen PS, Poulsen SS, Nexo E. Epidermal growth factor inhibits cysteamine-induced duodenal ulcers. growth factor inhibits cysteamine-ind

6 Bower JM, Camble R, Gregory H, Gerring EL, Willshire IR. The inhibition of gastric acid secretion by epidermal growth factor. Experentia 1975; 31: 825-6.

7 Malo C, Menard D. Influence of epidermal growth factor on the development of suckling mouse intestinal mucosa. Gastroenterology 1982; 83: 28-35.

8 Oka Y, Ghrisan FK, Greene HL, Orth DN. Effect of mouse epidermal growth factor/urogastrone on functional maturation of rat intestine. Endocrinology 1983; 112: 940-4.

9 Calvert R, Beaulieu JF, Menard D. Epidermal growth factor (EGF) accelerates the maturation of foetal mouse intestinal mucosa in utero. Experentia 1982; 38: 1096-97.

10 Chabot JG, Payet N, Hugon JS. Effects of epidermal growth factor (EGF) on adult mouse small intestine in vivo and in factor (EGF) on adult mouse small intestine in vivo and in
organ culture. Comp Biochem Physiol 1983; 74: (A) 247-52.

11 Ulshen MH, Lyn-Cook LE, Raasch RH. Effects of intraluminal epidermal growth factor on mucosal proliferation in the small intestine of aduit rats. Gastroenterology 1986; 91: $1134-40$.

12 Al-Nafussi AI, Wright NA. The effect of epidermal growth factor (EGF) on cell proliferation of the gastrointestinal mucosa in rodents. Virchows Arch [B] 1982; 40: 63-9.

13 Dembinski A, Gregory H, Konturek SJ, Polanski M. Trophic action of epidermal growth factor on the pancreas and
gastroduodenal mucosa in rats. $\mathcal{F}$ Physiol $1982 ; 325: 35-42$.

14 Majumdar APN. Postnatal undernutrition: effects of epidermal growth factor on growth and function of gastrointestinal tract in rats. $\mathcal{F}$ Pediatr Gastroenterol Nutr 1984; 3: 618-25.

15 Goodlad RA, Wilson TJG, Lenton W, Gregory H, McCullagh $\mathrm{KG}$, Wright NA. Intravenous but not intragastric urogastrone-EGF is trophic to the intestine of parenterally fed rats. Gut 1987; 28: 573-82.

16 Al-Mukhtar MYT, Polak JM, Bloom SR, Wright NA. The search for appropriate measurements of proliferative and morphological status in studies of intestinal adaptation. In: Robinson JWL, Dowling RH, Reicken E-O, eds. Mechanisms of intestinal adaptation. Lancaster: MTP Press, 1982: 3-25.

17 Finney KJ, Ince P, Appleton DR, Sunter JP, Watson AJ. A trophic effect of epidermal growth factor (EGF) on rat colonic mucosa in organ culture. Cell Tissue Kinet 1987; 20: 43-56.

18 Konturek JW, Bielanski W, Konturek SJ, Bogdal J, Oleksy J. Distribution and release of epidermal growth factor in man. Gut 1989; 30: 1194-200.

19 Forgue-Lafitte ME, Laburthe $M$, Chamblier MC, Moody AJ, Rosselin G. Demonstration of specific receptors for EGFurogastrone in isolated rat intestinal epithelial cells. FEBS Lett 1980; 114: 243-6.

20 Gallo-Payet N, Hugon JS. Epidermal growth factor receptors in isolated adult mouse intestinal cells: studies in vivo in in isolated adult mouse intestinal cells: studies

21 Chabat J-G, Walker P, Pelletier G. Demonstration of epidermal growth factor binding sites in the adult rat small intestine by autoradiography. Can $\mathcal{F}$ Physiol Pharmacol 1987; 65: 109-12.

22 Conteas CN, DeMorrow JM, Majumdar APN. Effect of epidermal growth factor on growth and maturation of fetal and neonatal rat small intestine in organ culture. Experientia $1986 ; 42: 950-2$.

23 Menard D, Arsenault P, Pothier P. Biologic effects of epidermal growth factor in human fetal jejunum. Gastroenterology 1988; 94: 656-63.

24 Gregory $\mathrm{H}$. Isolation and structure of urogastrone and its relationship to epidermal growth factor. Nature 1975; 257: 325-7.

25 Goodlad RA, Wilson TG, Lenton W, Wright NA, Gregory H, McCullagh KG. Urogastrone-Epidermal growth factor is
trophic to the intestinal epithelium of parenterally fed rats. trophic to the intestinal epithe

26 Walker-Smith JA, Phillips AD, Walford N, Gregory H, Fitzgerald JD, McCullagh K, Wright NA. Intravenous epidermal growth factor/urogastrone increases small intestinal cell proliferation in congenital microvillous atrophy. Lancet 1985; ii: 1239-40.

27 Wheeler EE, Challacombe DN. Influence of 5hydroxytryptamine on crypt cell production rate of human duodenal mucosa cultured in vitro. F Clin Pathol 1987; 40: $710-3$. 